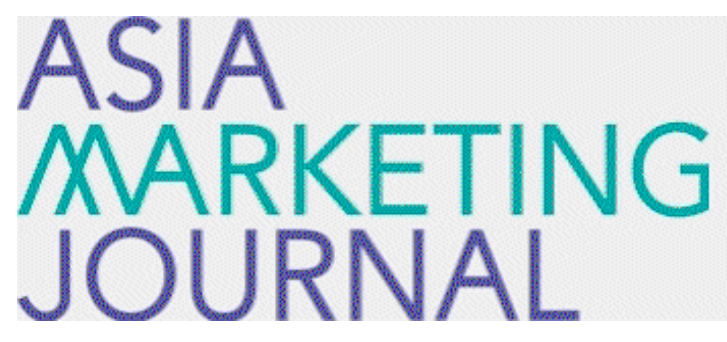

ASIA MARKETING JOURNAL

Volume 14 | Issue 4

Article 10

$1-30-2013$

\title{
Jeju Air: Branding of a K-Pop Airline
}

Wu Jin Chu

Eun Soo Baek

Eyung Pyo Ko

Follow this and additional works at: https://amj.kma.re.kr/journal

Part of the Marketing Commons

\section{Recommended Citation}

Chu, Wu Jin; Baek, Eun Soo; and Ko, Eyung Pyo (2013) "Jeju Air: Branding of a K-Pop Airline," Asia Marketing Journal: Vol. 14 : Iss. 4 , Article 10.

Available at: https://doi.org/10.53728/2765-6500.1506

This Article is brought to you for free and open access by Asia Marketing Journal. It has been accepted for inclusion in Asia Marketing Journal by an authorized editor of Asia Marketing Journal. 


\section{Jeju Air: Branding of a K-Pop Airline*}

\section{Introduction}

South Korea's LCC (Low Cost Carrier) industry, which started from the 2000s, brought upon a new lifestyle within the country. In Korea, unlike European or U.S. markets, air travel was limited and previous domestic airlines mostly focused on the business sector. The LCC industry had a shaky start with high initial investment and low load factors, but soon started to take root as they started to take over the domestic market and competed for overseas routes, making air travel a reality for the masses. Today, profitability of low-cost airlines have been improving as their routes expanded and load factors went up, especially in routes connecting China, Korea and Japan. Also, greater aircraft usage by utilizing "red-eye" flights to Southeast Asian destinations greatly

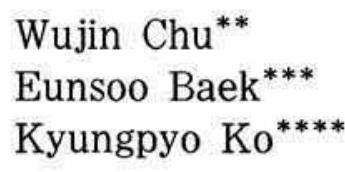

improved the efficiency of aircraft operations. Further, the decrease of the public's initial rejection of low-cost airlines also served as a contributing factor. A significant portion of the market for domestic flights is now owned by low-cost airlines. The market share of domestic flights for low-cost airlines, which was only $2.17 \%$ in 2006 , increased to $9.72 \%$ in 2008 , to $27.35 \%$ in 2009 , and to $34.1 \%$ in 2010 . In the first half of 2011, the market share for domestic flights went over $40 \%$. An industry specialist pointed out, "because domestic flights have short travel distances, price is more of a significant factor than service. Comparatively, this provides a structure in which low-cost airlines can easily advance." Even in short-distance international flights such as flights to Japan, the advancement of low-cost airlines is continuing as of today.

Jeju Air, which has shown the fastest growth

\footnotetext{
* This paper has received financial support from Marketing Research Center, Seoul National University, Also, authors thank Minjung Roh and Ross Chu for their research assistance.

** Seoul National University (wchu@snu.ac.kr), corresponding author

*** Seoul National University

**** Jeju Air
} 
rate among all domestic low-cost airlines, has exceeded 2 billion won in sales in 2011. Since its inaugural flight in 2006, its average yearly growth rate was $91 \%$, and it has been earning surplus profits since the second half of 2010 . In 2011, Jeju Air's sales from international flights began to exceed those of domestic flights. In the fast growing market for low-cost airlines, there are many airlines from other Asian countries competing in the same market. In terms of price, Korean LCCs are positioned somewhere between a full service carrier (FSC) and a traditional LCC which charges as low as $50 \%$ of the FSCs fare. The ticket cost of domestic low-cost airlines is about 70\% 80\% that of major airlines such as Korean Air, or Asiana.

In the following case study, we will examine and analyze the results of brand building strategies of Jeju Air, which has secured a new competitive advantage in the intensifying competitive landscape and is pursuing a significant leap as an Asian LCC. Specifically, we will analyze and contrast the brand building strategies, various customer satisfaction activities, and service management programs of successful global LCC firms such as Air Asia, Jetstar, and JetBlue. Jeju Air has benchmarked their success factors, and such principles have been reflected in Jeju Air's brand building strategies, which began in April of 2012. Through the analysis of customer feedback collected in September of the same year, we aim to show the effectiveness and limitations of Jeju Air's brand building strategies as well as present future challenges.

\section{The Necessity of Brand Building for Jeju Air}

Jeju Air was started as a joint venture between Jeju Province and Aekyung Group. It is South Korea's $2^{\text {nd }}$ LCC, following on the heels of now defunct Hansung Airlines. After Korean Air and Asiana Airlines, Jeju Air is South Korea's $3^{\text {rd }}$ airline ever to receive regular air transportation business license. Two other LCCs subsequently entered this market, Jin Air and Air Busan, both subsidiaries of Korean Air and Asiana Airlines, respectively. In March 2009. Jeju Air was South Korea's first LCC airline to operate international flights. By 2010, Jeju Air had accumulated 11,545 domestic flights and 1.97 million assigned seats in their Jeju-Gimpo. Jeju-Gimhae, and Jeju-Chungju routes. For international flights, Jeju Air offered 3,387 flights along 11 routes including Incheon-Hong Kong, Incheon-Manila, Busan-Cebu, and other routes. As of January 2012, Jeju Air has the most international regular flights among all domestic LCC airlines. Recently, Jeju Air also expanded their network to include Guam. In total Jeju Air is operating in 6 countries and 9 cities with a total of 14 international flights daily.

However, the price position of Korean LCCs 
are somewhat modest compared to their US and European counterparts. Some point out that in order for a low-cost airline to expand on a higher level, it needs to lower their prices from their current level of $70 \% \sim 80 \%$ of already existing airlines to $50 \% \sim 60 \%$. Also, the operation of domestic LCCs is small and scale economies are limited, In the current state, all domestic low-cost airlines operate 12 aircrafts or under. Normally, in order for LCCs to lower costs and raise profits, it is generally agreed that at least 25 aircrafts are necessary. A worker in Jeju Air said, "There are high fixed costs associated with maintaining spare parts and training employees. We need to own more aircrafts in order to exceed fixed costs and create profits. By doing so, we would be able to offer cheaper airline ticket prices."

Domestic LCC airlines such as Jin Air, Air Busan, Eastar Jet, and T-way Airlines are not differentiated with Jeju Air at the moment, all providing a similar LCC experience at a lower cost than the full service carriers. In fact, most customers replied, in a recent survey, that they saw little difference between the LCCs in terms of service, concept, quality and value. In order to break away from the pack of mediocrity, Jeju Air began to implement brand building strategies. Another reason for brand building was the imminent entry of LCCs from other countries entering the Korean air space. Most notably. Air Asia, Jetstar and Tiger Airways were planning to enter the Korean market.
Because airline services are difficult to evaluate prior to purchase, the use of brands can reduce monetary and social risks that customers may perceive. Also, brands help customers visualize the formless service so that they can understand and trust the services offered by the firm. For such reasons, a brand strengthening strategy was necessary for Jeju Air at the moment. In doing so, Jeju Air wanted to build a brand that was relevant to both Korean customers and customers in countries that Jeju Air was flying to. The brand building effort started with an initial examination of Jeju Air's current image. Next, a thorough study was conducted on successful brand building efforts of foreign LCCs.

\section{Benchmarking of Successful LCCs}

\subsection{Air Asia}

Air Asia is Asia's LCC success story. Air Asia is a Malaysian airline that started off as a FSC (full service carrier) in 1996. It started off as Malaysia Airline's rival, but inevitably faced trouble as competition intensified. In 2001. Time Warner's ex-board member Tony Fernandez established the Tune Air holding company and purchased Air Asia, switching the company towards the direction of a LCC firm. Tony 
Fernandez recruited the head of Ryanair, Connor McCarthy, and thus established the LCC business model. It set its headquarters in Kuala Lumpur International Airport and offered cheap fares. As a result, it was able to overturn the domestic monopoly system set by Malaysia Airlines and began creating profits from 2003. In order to maximize the efficient use of Kuala Lumpur International Airport's utilities, which remained underused back then, they were able to gain government support as they established Air Asia. Because competition between nearby international airports increased and Asia's middle class experienced a sudden economic growth, it was the perfect environment for Air Asia to enter the LCC market.

In 2003 as the LCC boom started taking place in Southeast Asia, many new LCC airlines were started and the LCC market reached its fully developed state. Airlines started during this period included ValueAir. Tiger Airways, and One-Two-Go. As Air Asia responded to such developments, it recognized that simple low-price tactics will soon lead to cutthroat competition, and it began to implement brand building tactics. They created the slogan "Now Everyone Can Fly," offering a simple but clear vision to tear down walls of social and economic classes to provide affordable prices to a wider audience. Doing so lowered the required standards of flying for many people. At the same time Air Asia emphasized safety, simplicity, and transparency as their corporate values. Air Asia went on a rapid expansion of their routes and fleet size to accelerate scale economies, thereby bring down prices even further. In addition, Air Asia charged for many services that were standard at FSCs, such as drinks, meals, second checked baggage. Again this practice of ancillary pricing brought in revenue so that base tickets prices could be lowered even further.

Moreover, Air Asia continued their free and specially priced tickets through various promotion campaigns, and they also complemented their low ticket prices by signing up with low-price hotels, online travel portals, to provide a low-cost package for its customers. On the other hand, Air Asia implemented a highcost sports marketing effort that included ties to Manchester United Football Club, Formula 1 Racing and the local sports leagues. The Manchester United, and Williams Formulal racing team sponsorships exposed the Air Asia brand to the world, and they were able to enhance awareness for the brand. Their marketing expense as a percentage of sales is presented in Figure 1.

Air Asia also put in considerable effort in establishing their business culture, which they felt was a central part of their brand asset. Air Asia supported in-company pilot training programs in order to manage employee experience and boost loyalty, allowed board members to wear casual attire instead of formal suits, and used first names in place of official titles. 
〈Figure 1〉 Air Asia's marketing expenses

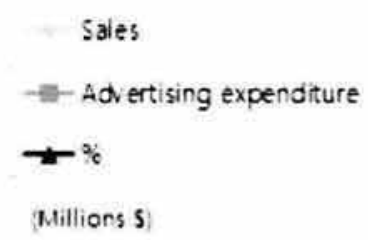

\section{$1,593,978$}

$1,047,082$

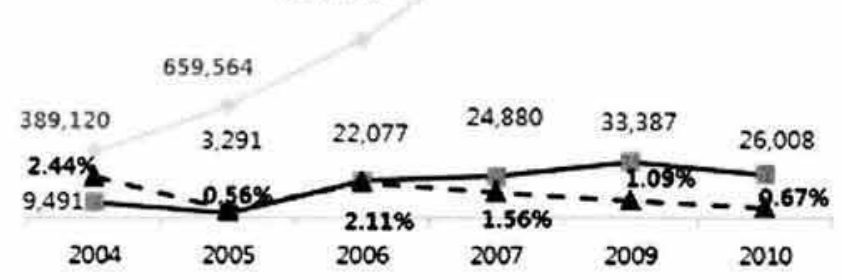

Activities such as these allowed undivided support for a free and open business culture. By focusing on such a pull marketing strategy based on a strong brand, Air Asia was able to rise from a US $\$ 200$ million dollar company (in sales) to a US $\$ 1.5$ billion company in just 5 years.

\subsection{Jet Star}

In 2000, Virgin Blue entered the Australian airline market and took away 30\% of Qantas' market. Faced with such dire circumstances and fighting for survival itself. Qantas began Jetstar in 2004, an Asia-Pacific LCC with its hub in Singapore. Although Jetstar was a late comer, it started with a huge marketing blitz and quickly found its market. One strength of Jetstar was that it offered longer flights than the traditional LCCs, which only traveled to venues inside 4 flight hours. Also, by merging with Value Air in 2005, a Singaporean LCC, Jetstar managed to connect Quantas customer to all destinations in the Asia Pacific region. At the same time, advancements were made into Hong Kong. Japan, and China. As a result, Jetsar's LCC advances were effective in taking back markets that were previously lost to Virgin Blue.

However, competition with Virgin Blue and other LCCs was creating an environment of vicious price competition, a clearly unsatisfactory situation. To respond to this situation. Jetstar 
〈Figure 2〉 Marketing Strategies of Air Asia

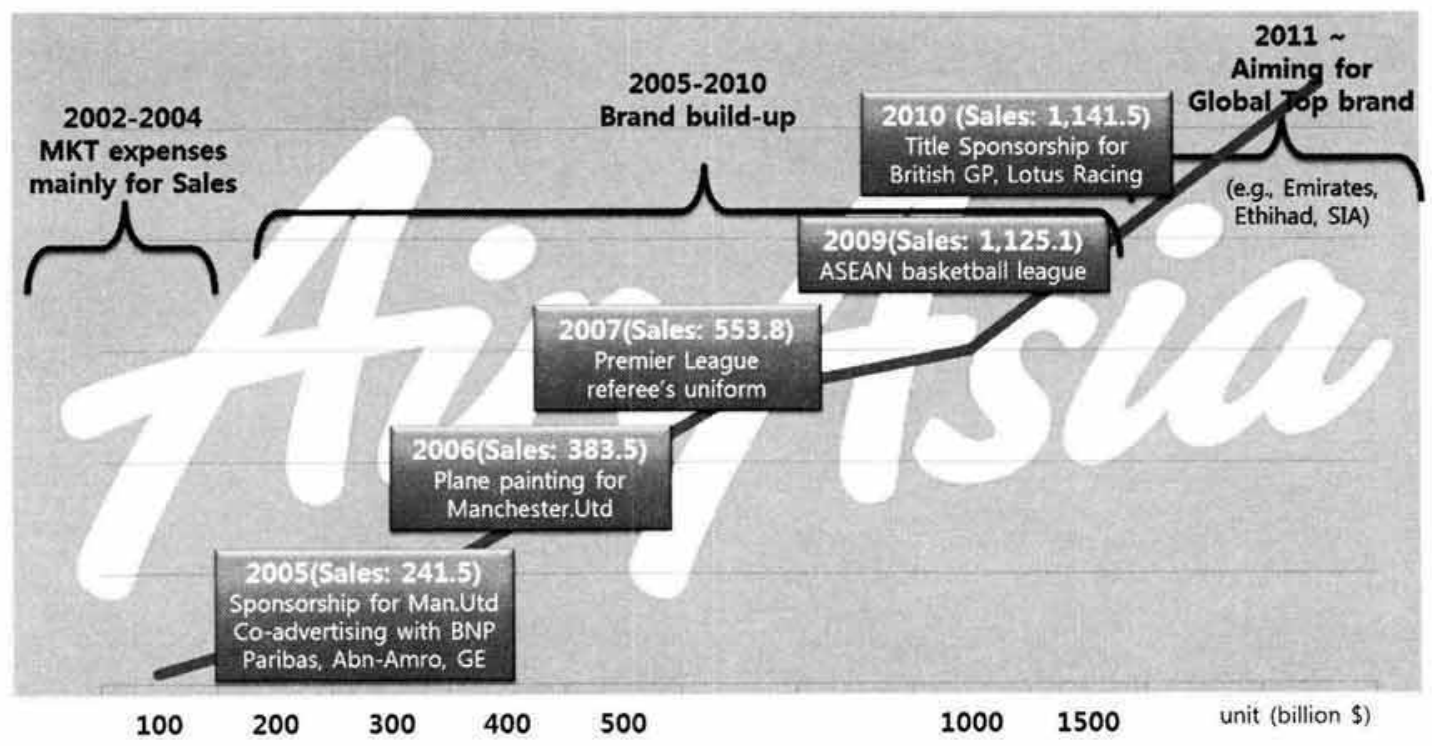

accelerated M\&A strategies, and began to implement brand building strategies 〈Figure 3$\rangle$. Jetstar used the slogan "OZjet, Australia's No. 1 Fares Airline," which promoted the airline's Aussie heritage. It also used the orange color to provide a simple but differentiated brand identity as well as emphasize fun, openness, and safety. By doing so, Jetstar was able to create a coherent brand concept. Jetstar also made use of internet eWOM (electronic wordof-mouth) and sports marketing. In the early years, marketing funds were not held back on brand building projects and Jetstar used AU $\$ 15$ million dollars on advertisements at the time of launch, which resulted in 20,000 daily hits on their website. Also in 2008, Jetstar made a SNS promotion involving 1000 special seats for only 2 cents to commemorate their 5th anniversary. As they advertised this promotion through Twitter, they were able to sell all of these seats within an hour.

In order to advance from a local to a regional brand, Jetstar first worked with Singapore's Tourist Authority to develop focused promotions on flights to Singapore. In doing so, Jetstar's promotion of tours to Singapore appealed to a wide spectrum of audiences in Singapore, Indonesia, Malaysia, Hong Kong. Taiwan, Philippines, Thailand, and Vietnam through newspapers, radio, and internet portals. After preparations were made with the Singaporean agency, Jetstar started airing advertisements in Australian TV with the message "Fly more places, more often, for less." Moreover. Jetstar solidified its brand value as an official native-born Australian firm as it began to pursue sports marketing in 
2007 and provided sponsorship to the Gold Coast Titans, a team that is a part of Australia's National Rugby heritage.

\section{〈Figure 3〉}

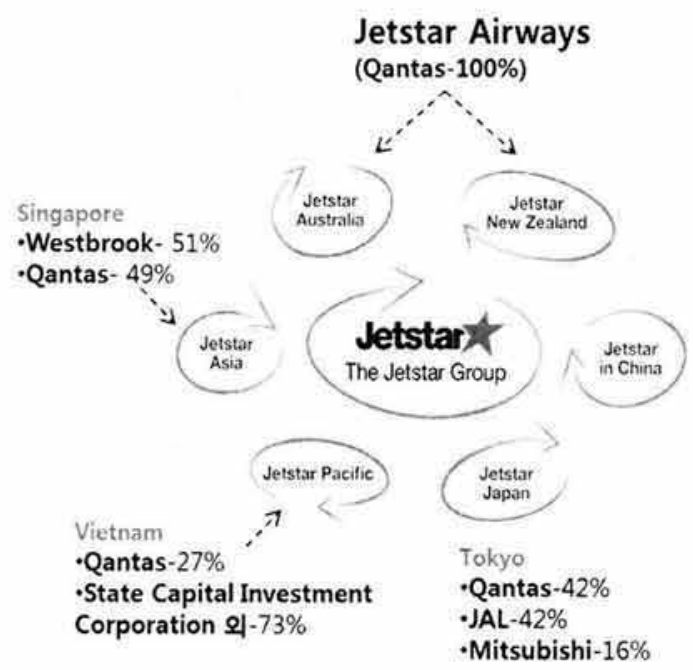

\subsection{JetBlue}

David Neeleman was exposed to a variety of experiences as he worked under Southwest Airline's CEO, Herb Kelleher. Based on such experiences, Neeleman established JetBlue in 2000 as a new LCC brand. At the time of establishment, investors were eager enough to fund US $\$ 200$ million to the new venture. The mission of Jet Blue was to "Bring Humanity Back to Air Travel." This theme seemed to hit a note with travelers who were getting a little bit annoyed by LCC tactics that were pushing customers to the limits of their comfort zones. In order to differentiate itself, JetBlue chose
JFK international airport as its main hub airport because JFK afforded accessibility and less congestion. However for the very same reasons, JetBlue avoided LA International and chose nearby Long Beach Airport as their west coast hub.

JetBlue came up with the motto "A new low-cost airline with its home base in New York" and differentiated itself by stating that it provided a better service with reasonable prices. JetBlue aimed at targeting previous LCC consumers who were tired of low-quality customer services, the lack of in-flight entertainment facilities, ancillary charges, flight delays, and various other discomforts of traveling on an LCC. Despite being a low-cost airline, JetBlue emphasized "service, service, service" mindset. JetBlue's brand value successfully found its place as the name "JetBlue" became synonymous with "customer service". This was the result of JetBlue's efforts on brand construction that included differentiated in-flight entertainment facilities, new aircrafts, leather seats, and more leg room. Soon after, JetBlue created a "True Blue" loyalty program in order to solidify its brand: this program would build and maintain JetBlue's loyal customers.

As market share increased, JetBlue was able to achieve a unique position in the market. JetBlue was able to ascend as a differentiated competitor not only in the LCC market but also in FSC markets occupied by Delta, United and Continental. In 2007, JetBlue was $8^{\text {th }}$ in 
passenger traffic and $10^{\text {th }}$ in sales among all US carriers. With regards to customer satisfaction, JetBlue has been maintaining the number 1 spot for 8 straight years in the J.D.Power Survey.

To form an emotional bond with New Yorkers, JetBlue became the official airline of the Jets, an American football team based in New York. JetBlue later formed a linkage with the Red Sox, since Boston was another important destination for JetBlue. JetBlue's unconventional"All You can Jet" promotion, allowed customers to have unlimited passes to flights and seats regardless of distance and number of flights flown during the off-season months of September and October. This promotion allowed JetBlue to fill in empty seats during the off-season months, and this became a part of the buzz marketing program and was handed down through SNS. As a result, JetBlue was able to create awareness and acquire new customers, although the promotion was not effective in creating real profits 〈Figure 4-1〉.

In 2010, JetBlue's new slogan and campaign
"You Above All"was created by the Mullen advertising agency. By implementing this campaign, they established their core identity of "customer-centeredness" by putting their customers at their utmost priority.

\subsection{Implications for Jeju Air's Branding}

The comprehensive benchmarking resulted in the following implications for Jeju Air.

- Advertising-to-sales ratio should be higher in the initial stage of brand building.

- The brand slogan is very important.

- Use the aircraft to promote the brand.

- Sponsorships should be medium to longterm.

- There's a need for a distinctive image, beyond "fun and friendly."

Benchmarking successful LCCs also revealed that they commonly reached success through a differentiated positioning achieved through strong brand building strategies. The summary of

〈Figure 4-1〉 (left) All You Can Jet promotion; 〈Figure 4-2〉 (right) You Above All campaign
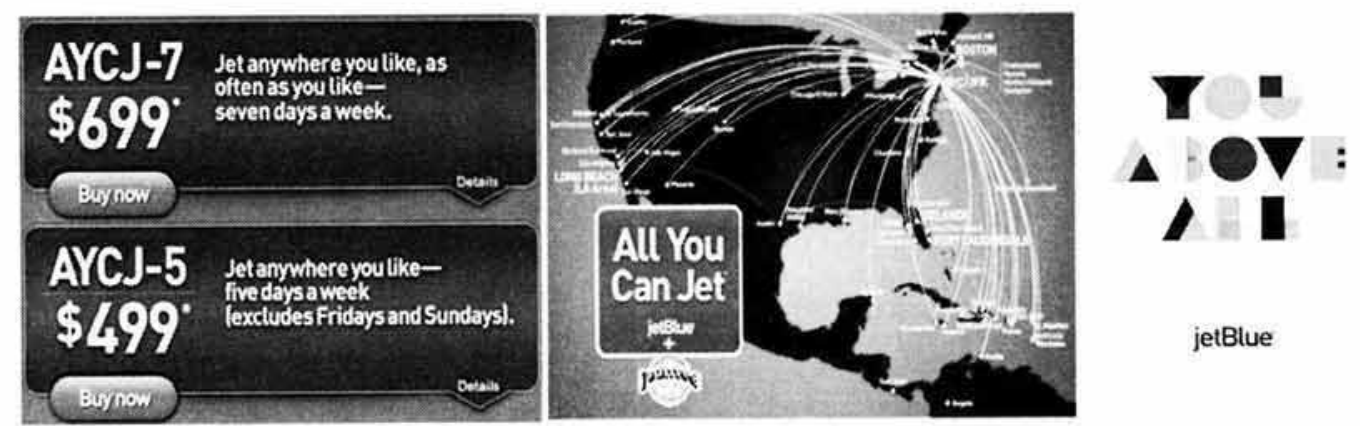
〈Figure 5〉 JetBlue's marketing and change in selling expenses
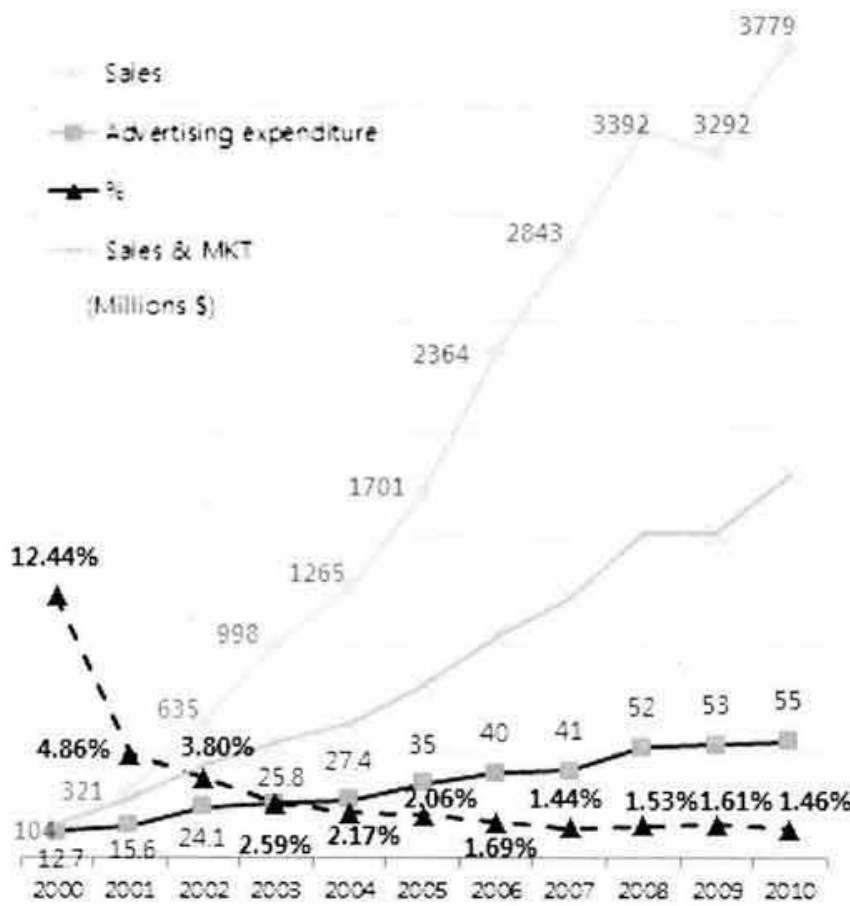

such strategies are as follows. First, in terms of the advertising and marketing ratios, high ratios were maintained in the early stages of the launch and were reduced later. However, the absolute amount continued to increase. By observing Figure 5, one can observe that JetBlue's ratio of advertisements expenditure to sales in its early stages of establishment (2001) comprised a big portion of $12.44 \%$. That ratio gradually decreased and was maintained at an average of $1.5 \%$.

Second, slogans have a significant impact on brand building. Slogans including AirAsia's "Now everyone can fly" and JetBlue's "You above all" have provided a simple but consistent message, thus constructing a powerful brand position and helping these firms become internationally acknowledged as a well-positioned international brand.

Third, continual sponsorship activities were utilized as powerful brand communication methods. AirAsia`s Manchester Utd., Formula 1 Williams, British Grand Prix title sponsor was an international annual event that went beyond Asia, and this allowed AirAsia to become known worldwide and raised the firm's awareness and reliability, which acted as an important component for brand building. For the most part, sponsorships that have started in this matter were usually maintained without interruption. 
Moreover, some firms have actively made use of airframe painting and other communication methods for sponsorship. Jetstar's Australian Rugby league team, Gold Coast Titans, and JetBlue's New York Jets are examples of official sponsoring airlines that have made use of airframe painting, thereby displaying an unconventional communication method through even changing the airline's $\mathrm{CI}$ color.

Fourth, these firms have put in effort to build a differentiated image from the previous FSCs, and such efforts are evident through the emphasis on images relating to fun, passion, and funkiness. For instance, Jetstar introduced a $1+1$ free ticket promotion every year at their anniversary, which they called 'Bring a Friend For Free'. This highly contrasted to the heavy image previously presented by FSCs that often related to business and family-sized travelers. The new and differentiated image involved providing an everyday travel experience, just like a close friend.

By reflecting on these suggestive points, Jeju Air deduced its brand concept. Through various brand communication tools, brand building strategies were expected to satisfy Jeju Air's medium-term goals in areas of awareness, understanding, and preference. The goal was to achieve almost universal awareness in the domestic market while having an impact among Asian travelers. In terms of brand concept, Jeju Air wanted to be portrayed as friendly and exciting to domestic customers. and dynamic and "Korean" to international travelers. Other goals were to catch up with Asiana and Korean Air in terms of preference and repurchase intention.

\section{The Jeju Air Brand}

\subsection{Determining the Brand Concept}

Jeju Air's vision is to be the No. 1 LCC in Asia. From the start, its management rested on six key values, which were "safety first. reasonable price, trusting, caring and friendly." However, these values were universal among most LCCs and Jeju Air needed a distinctive brand image of being a young and dynamic company. Further, initial market research showed that Jeju Air's image was tied very strongly with Jeju Island, a quiet-peaceful resort island at the southern tip of the Korean peninsula. The negative connotation of this tie was "backward and slow," the opposite of what the company wanted to project.

A brand concept study was conducted to measure consumer response to various concepts, and among them most consumers liked the "fun and friendly"concept the best. Therefore, a more dynamic and trendsetting image was deemed to be the way to go. The orange color was also helpful in projecting a fresh and young image of the company. This concept resonated 
particularly well with consumers aged 20 39, Jeju Air's main target.

The centerpiece of this strategy was to project an image as the "K-Pop" airline. Korean dramas, music and music video has been growing in popularity since the early 2000, and culminated with the popularity of the "Gangnam Style" video, which hit 600 million views on YouTube and made $\# 2$ in the Billboard singles chart for six weeks. Because K-Pop is a strongly Korean phenomenon, it was a position that only a Korean carrier could take up, allowing Jeju Air to differentiate itself from other Asian LCCs. In addition to the K-Pop con- cept, supporting elements of the brand concept are shown in 〈Figure 6-1〉

Since Jeju Air was striving for a higher portion of FIT (Free Individual Traveler) customers, minimizing the travel agents role, a strong "pull" marketing strategy was needed with a strong brand and advertising. Both outbound Korean and inbound Asian customers could identify with the fun, friendly, and exciting image of K-Pop.

\subsection{Brand Building Tools}

As a brand building tool, Jeju Air signed with

\section{〈Figure 6-1〉 Brand Concept}

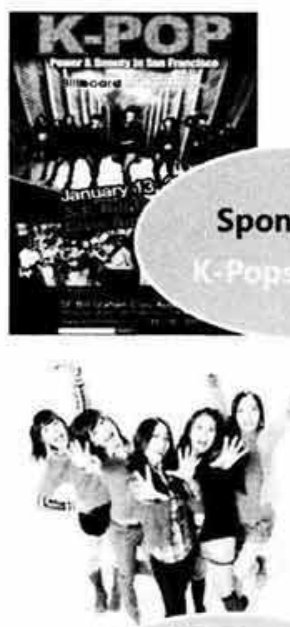

Association

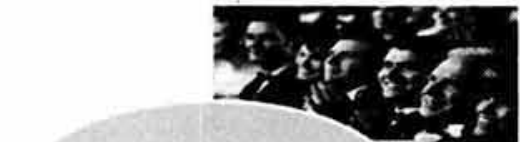

Brand Vision

\section{Jeju Air}

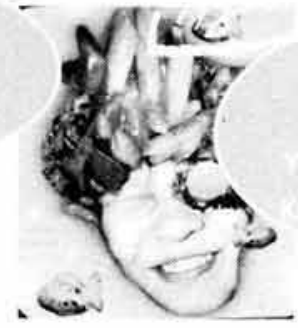

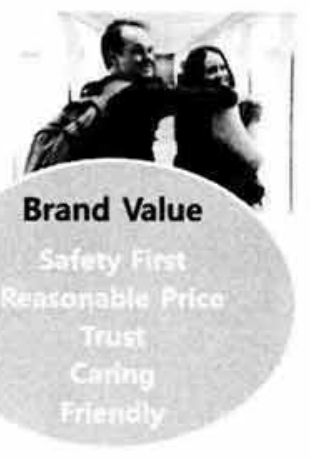

Slogans

\section{Brand}

Personality

\section{Exciting Korean}
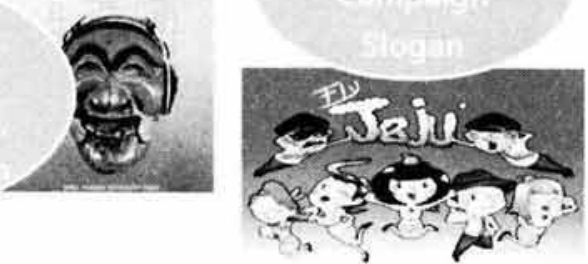
"Big Bang" a popular K-Pop guy-group with a strong following throughout Asia. At the time of signing "Big Bang" was \#1 in the Korean Charts with their new album. Big Bang was also planning a big Asian tour, starting with Nagoya, Japan, moving on to other cities in Japan, and then to China, Vietnam, Philippines, and Thailand. Jeju Air would use Big Bang in all of their ads (TV, Billboard, Buses, Internet, etc.) and also be their tour sponsor. The signing of Big Bang was a courageous move because the top K-Pop stars typically commanded US \$1 million per year for sponsorship 〈Figure 6-2〉

〈Figure 6-2〉 K-pop sponsorship
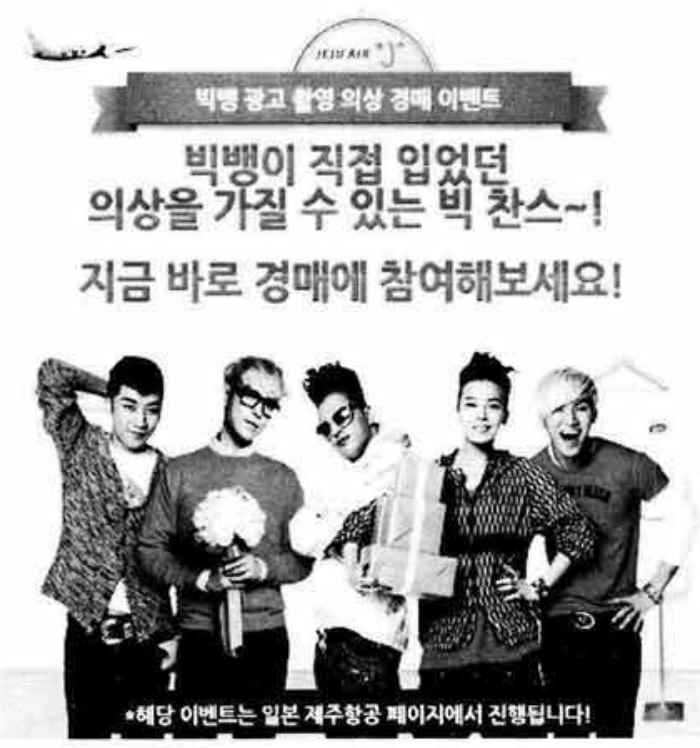

To maximize the impact of the model sponsorship, Jeju Air wrapped one of their 737s with a Big Bang poster, taking cues from airlines such as Delta (Walt Disney), and Air
Asia (Manchester United), at a cost of US $\$$ $50 \mathrm{~K}$. Big Bang would ride this wrapped plane into the cities for their concerts, where thousands of die-hard fans and media would be waiting at the airport, providing a great photo opportunity for Jeju Air and its plane.

The use of the model was also helpful in sprucing up Jeju Air's website. Rather than having a plain website with just flight and price information, Jeju Air's website was colorfully adorned with Big Bang photos and numerous interesting events, many of which had some connection with the K-Pop group. Each of the members of Big Bang was representing one of the popular destinations that Jeju Air was flying to. In addition, Jeju Air-Big Bang sites were opened up on Facebook and Twitter. Facebook and Twitter was particular effective in drawing fans from all over Asia into the Jeju Air brand.

Finally, advertising was conducted on IPTV and public transportation (subway, buses, stations). Partly, due to budget limitations most advertising took place BTL (below-the-line). However BTL ads proved to be effective in gaining greater frequency with the airline's target customer group.

Prior to Big Bang, Jeju Air's original image of "fun and friendly" did not take hold. In fact, the image was the opposite of what the company had hoped for. However, the K-Pop equation made all the difference, and Jeju Airs image began to change in just six months. 


\section{Results of Jeju Air's Brand-Building Activities}

The use of Big Bang increased awareness both in Korea. Although awareness of LCCs were steadily on the rise even before the advertising campaign, the campaign increased Jeju Air's (aided) awareness above 50\% for the first time, and \#1 among all Korean LCCs. The following results were monitored through an online survey of 3,030 users of LCCs in Korea, after five months of the campaign launch.

\subsection{Awareness}

Figure $7-1$ shows that $36.7 \%$ of respondents said that the use of Big Bang in Jeju Air's marketing campaign was effective in increasing Jeju Air's image as an international airline.
Since Jeju Air only undertook BTL advertising. and the survey was conducted randomly from visitors of a portal site, it shows that at least $36.7 \%$ of the people have been aware of the campaign. The ability to reach $36.7 \%$ of the population on such a short time period is due to the use of the K-Pop star as their model. The data also shows that teens were particularly cognizant and favorable towards the use of Big Bang in Jeju Air's ads 〈Figure 7-1, 7-2〉.

\subsection{Overseas Response}

\subsubsection{Effect on FFP (Frequent Flier Program) Enrollment}

Due to tour sponsorship and online advertisement, foreigners' awareness of Jeju Air is increasing. When we examine the number of foreigners who have joined Jeju Air's FFP

〈Figure 7-1〉 The effect Big Bang on Jeju Air's image as an "international airline."

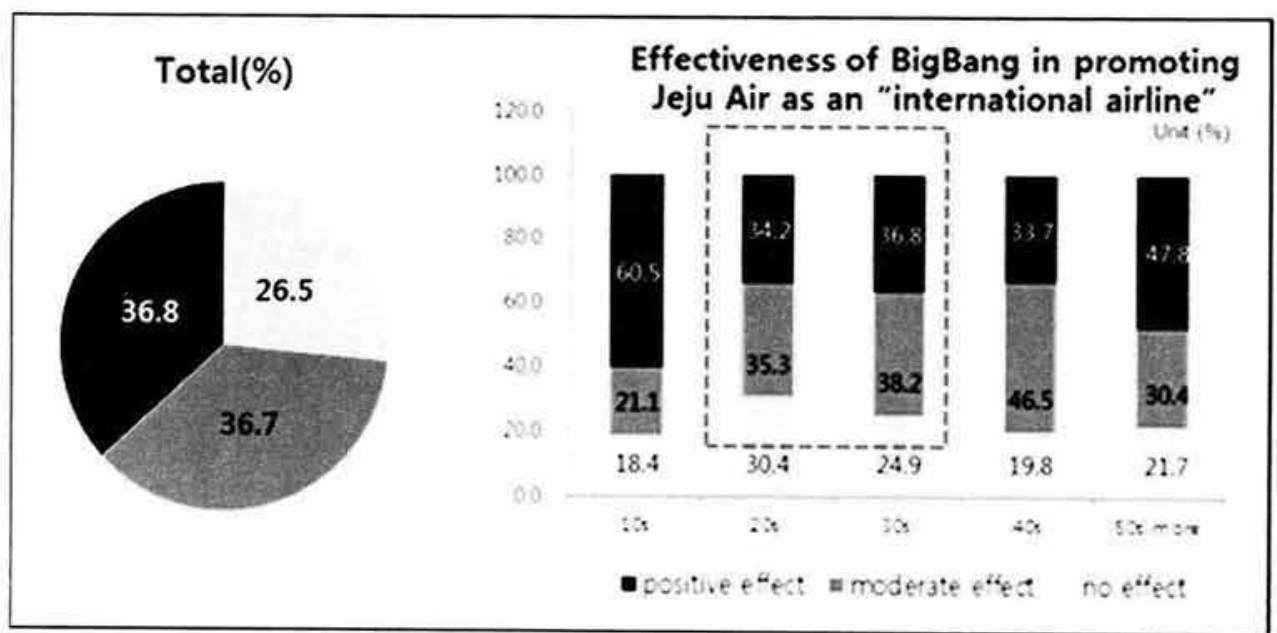


〈Figure 7-2〉 The effect Big Bang on Jeju Air's Positive Image

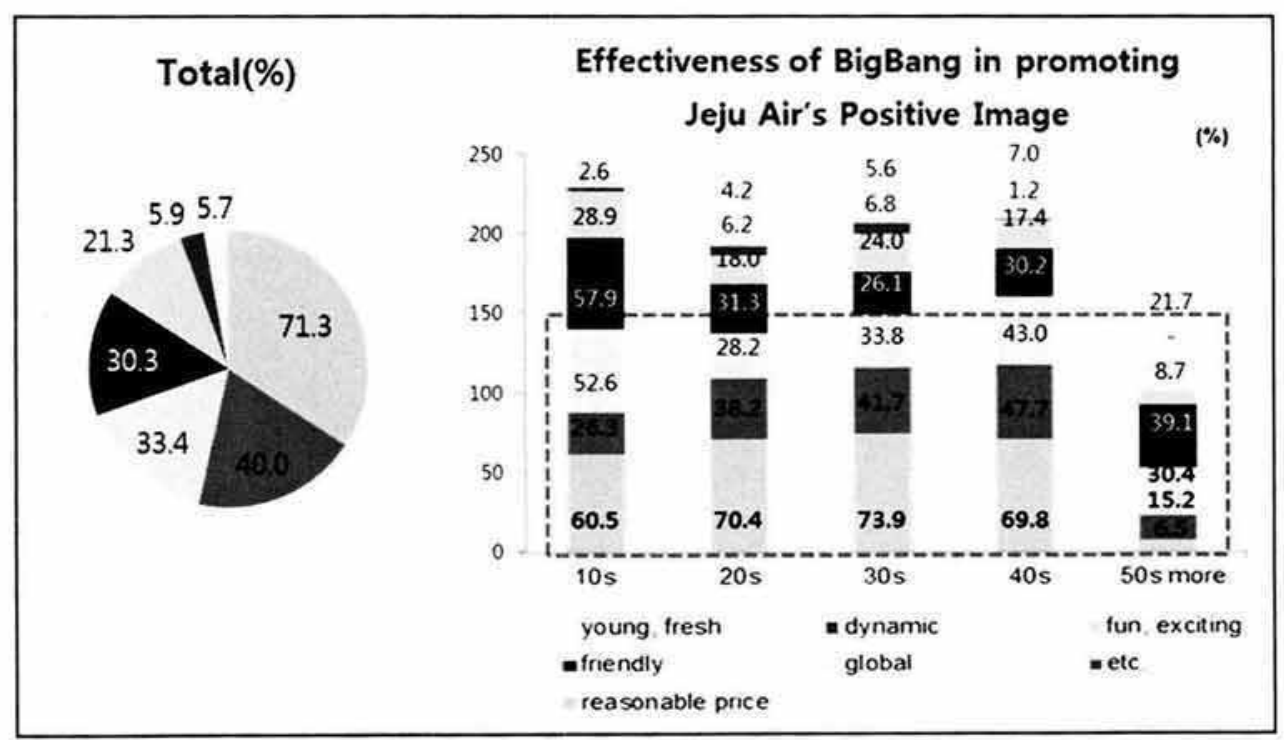

(frequent flyer program), it is recorded that immediately after the K-Pop campaign, enrollment increased $117 \%$ 〈Figure 8-1〉. In Japan, Jeju Air's largest international market, the number of people joining the FFP in the last 4 months exceeded the 3 year cumulative membership prior to the campaign 〈Figure 8-2〉. It is also interesting to note that Jeju Air discovered that FFP membership increased even in countries that Jeju Air does not yet serve. These types of evidence shows the power of using a regional star in reaching a very broad geographical area.

〈Figure 8-1〉 Overseas FFP Enrollment

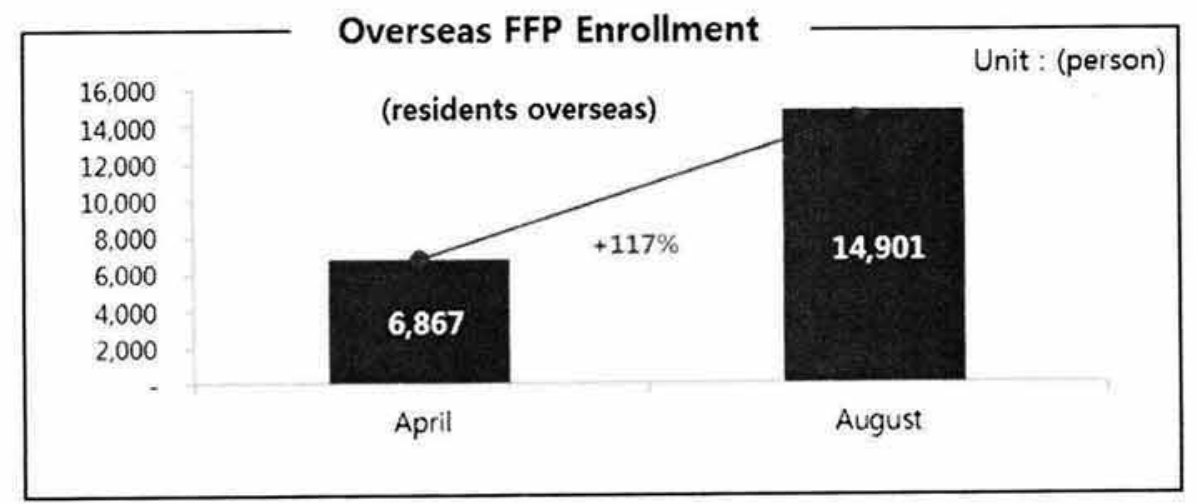


〈Figure 8-2〉 Number of Overseas FFP Members

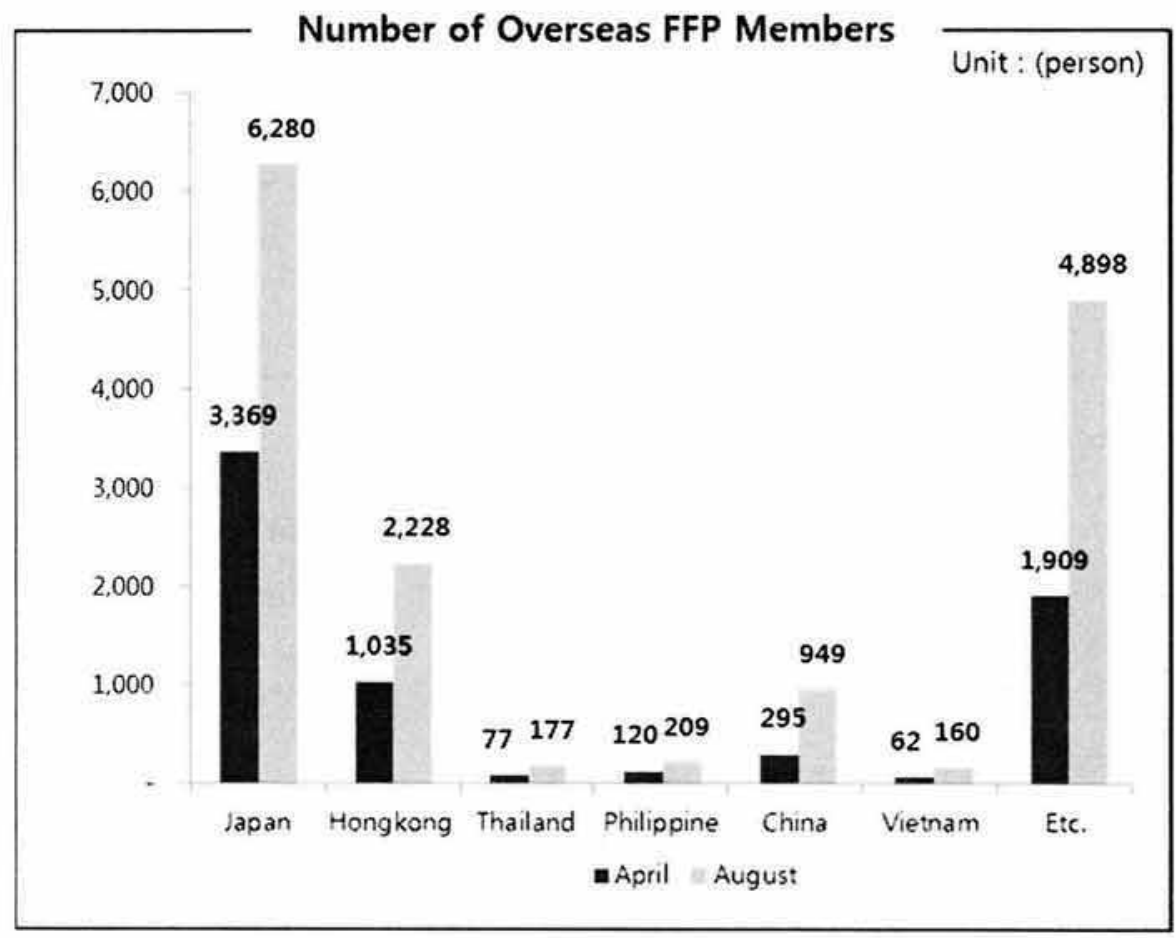

\subsubsection{SNS Activities}

Facebook fan page was established as part of the campaign in order to increase "buzz" value of Jeju Air's activities. It is noted that Facebook reception in Thailand, Philippines, Japan and Hong Kong is quite high. In fact, number of fans in Jeju Air's Facebook page is better or equivalent to some well-established carriers, who have started marketing through SNS much earlier. In Japan, since its opening in May $1^{\text {st }}$, there were approximately 10,000 fans after just 5 months. Facebook activity is also strong in Thailand, where K-Pop is in its peak acceptance 〈Figure 9-1.〉. Facebook membership was also high in countries that Jeju Air does not even fly to. This again, is the result of using a K-Pop star 〈Figure 9-3〉.

\subsubsection{Increase in Direct Selling for Inbound Passengers}

Due to Jeju Air's branding activities, direct selling increased for inbound passengers from Japan and Hong Kong. For both countries, the direct selling ratio increased 4.8 percentage points. This would be a significant achievement in terms of executing the LCC concept. This was due to a combination of model use as well as various promotions that were conducted 
〈Figure 9-1〉 Number of Facebook Fans Overseas

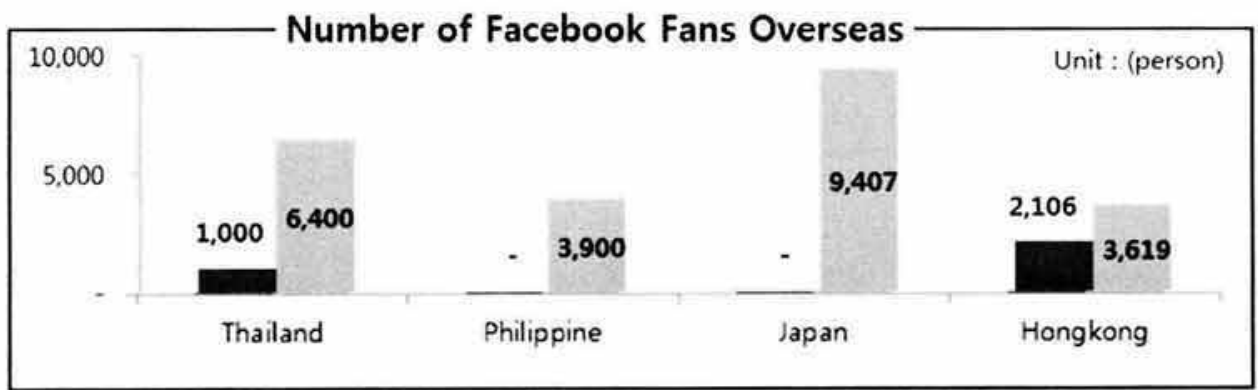

〈Figure 9-2〉 Number of Overseas Facebook Fans by Airline

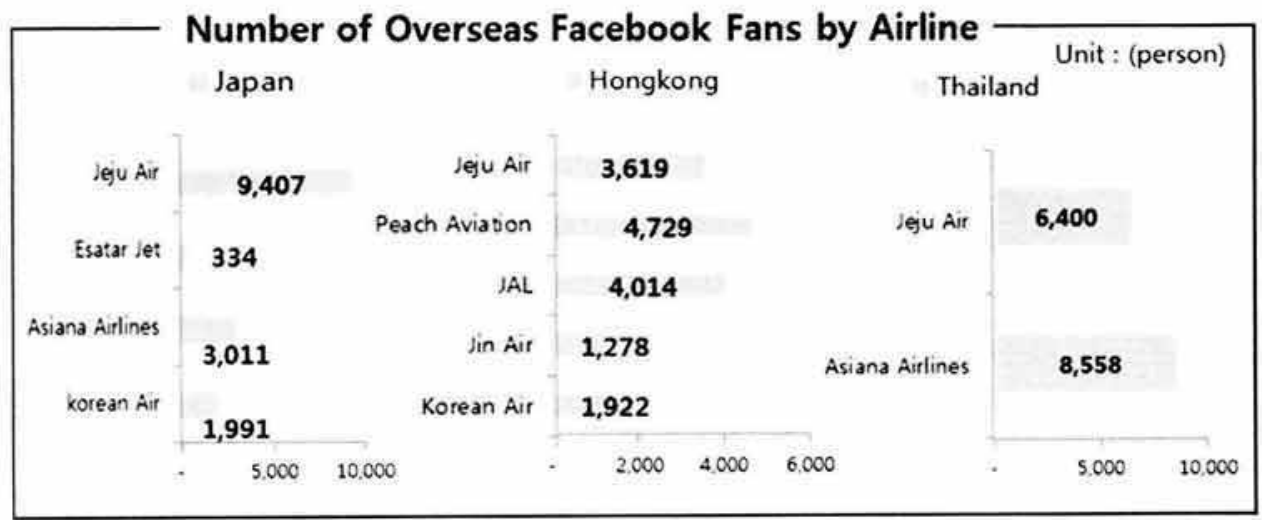

〈Figure 9-3〉 Number of Overseas Facebook Fans by Country

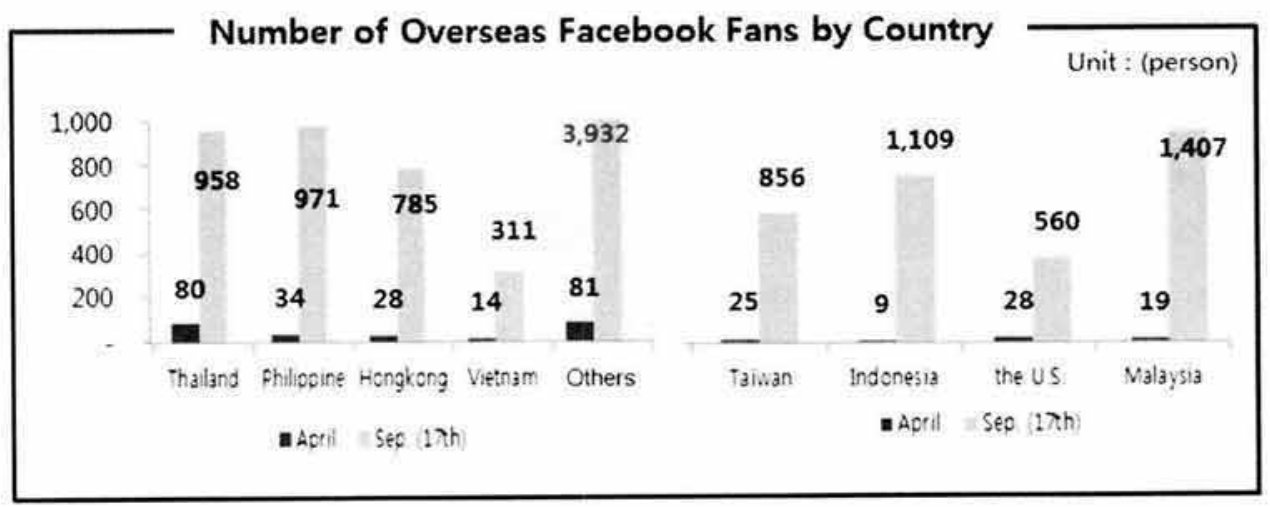

in conjunction with the launch of the market- Bang members as eye-catchers <Figure 10-1. ing campaign. The implementation of various 10-2>. promotions was enhanced by the use of Big 
〈Figure 10-1〉 Percentage of Direct Selling for Inbound Customers (Hong Kong)

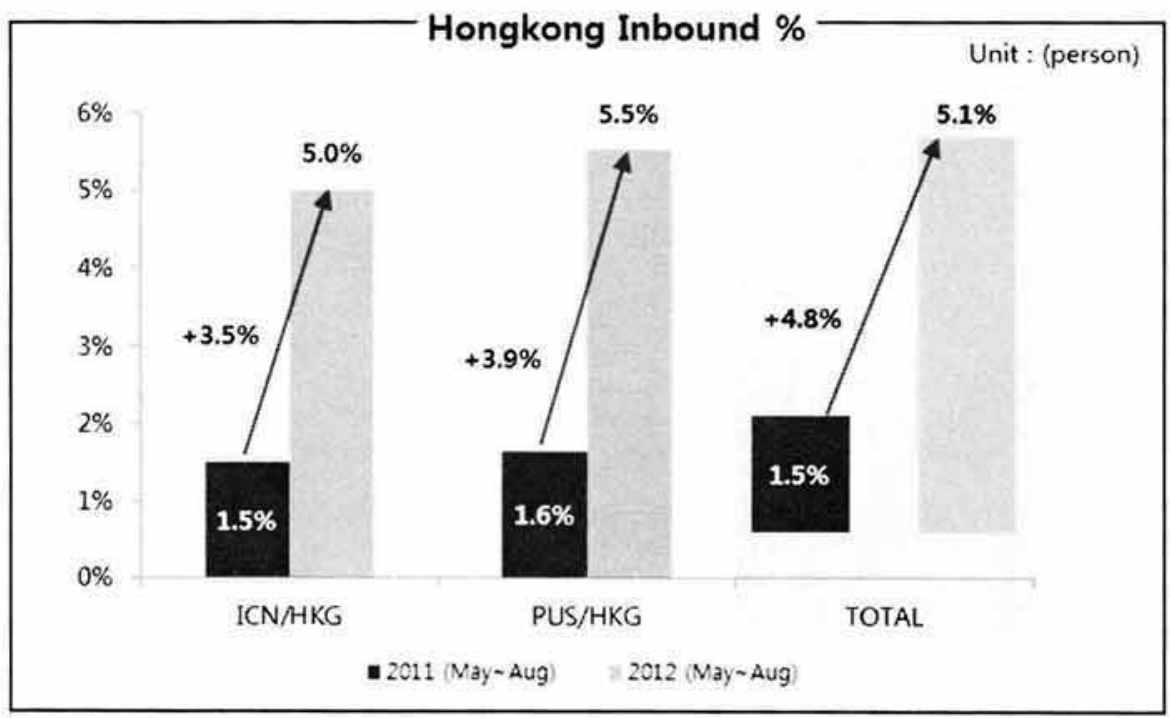

〈Figure 10-2〉 Percentage of Direct Selling for Inbound Customers (Japan)

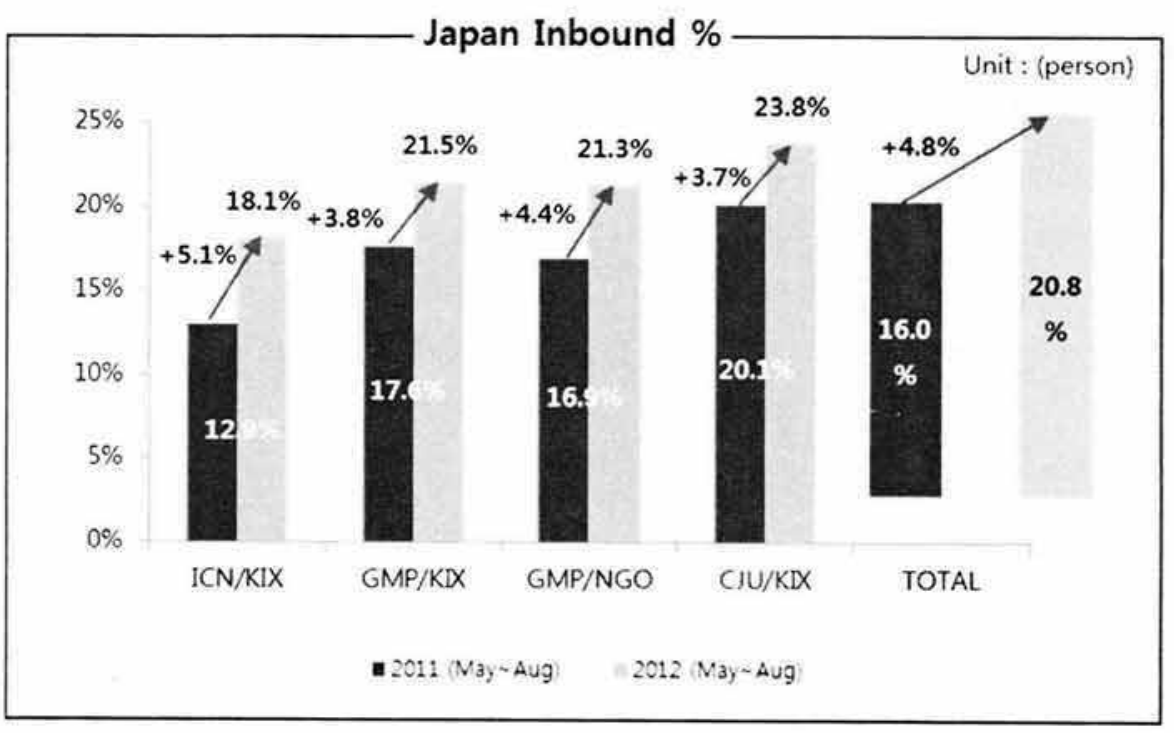

\subsubsection{Creating "Buzz"}

The biggest issue making was the planewrapping idea. A full-blown picture of the stars was used to wrap the Boeing 737 〈Figure 11〉. Some of the customer responses to using Big Bang design outside and inside the plane were as follows. 
〈Figure 11〉 Big Bang in front of "Wrapped Plane"

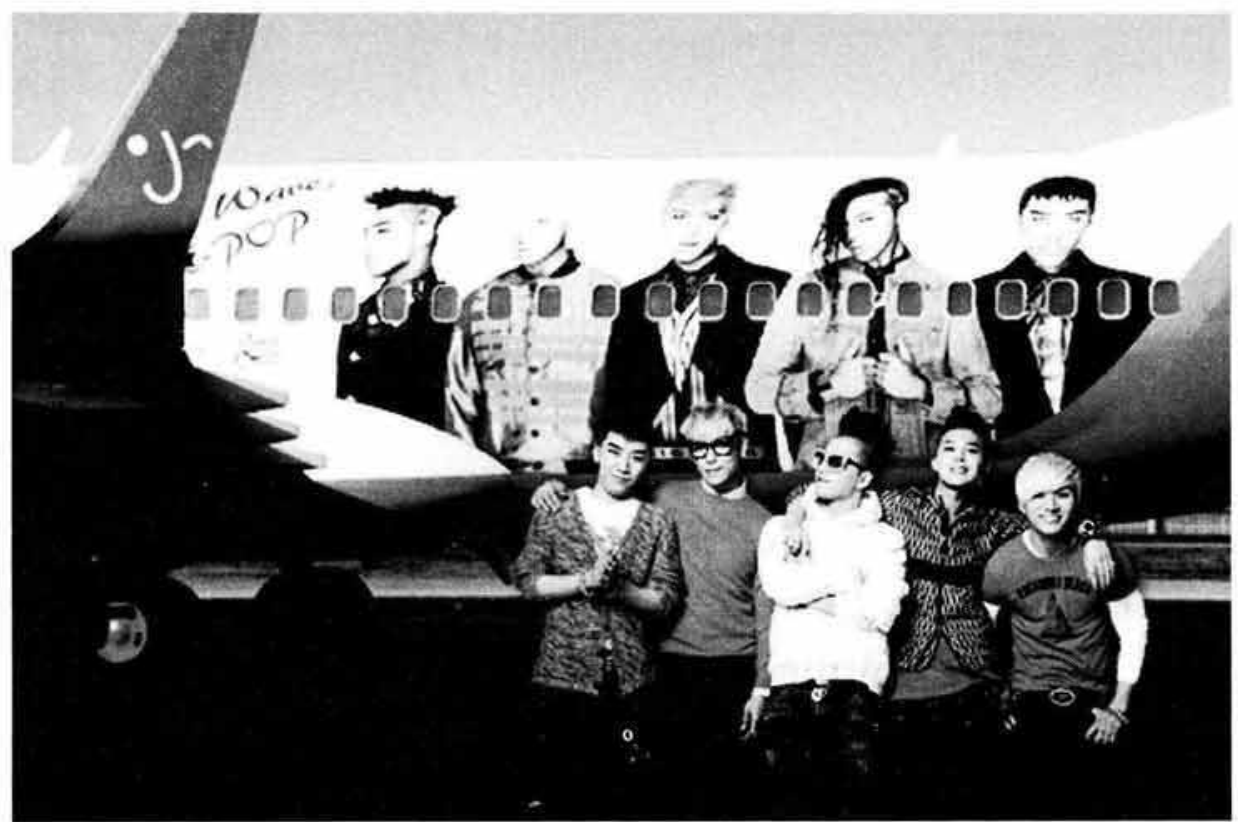

"Big Bang brightens up the plane"

"I really want to ride the Big Bang plane. When are you coming in to Tokyo?"

"Is Big Bang coming to Hong Kong in their wrapped plane?"

\section{Summary and Challenges}

\subsection{Factors of K-pop Success}

K-Pop and Jeju Air was a match made in heaven. Both entities were young, fresh and dynamic. The match between the product and the sponsor lead to a synergy effect. It is also interesting to note that the K-Pop phenomen- on was more apparent overseas than in Korea. The use K-Pop stars reduced the psychological barriers to flying with a relatively less-known Korean airline, for foreigners. While Air Asia, does not promote its national origin (i. e., Malaysia), Jeju Air has been quite forthright about its Koreanness. In a way this created a unique image for Jeju Air amongst all other non-Korean LCCs. Further Jeju Air's preemption of the K-Pop image meant that other Korean LCCs would have to look for a different positioning angle.

Although it is difficult to establish an ROI in terms of sales or profits, there has been a lot of publicity both through the media and through music videos and concert sponsorships. In the future, there is also a possibility of including 
K-Pop performances into Jeju Air’s travel package.

\subsection{Challenges for the Future}

K-Pop's popularity continues to be on the rise 〈Figure 12〉. The recent success of Psy's "Gangnam Style" video has added fuel to the fire. However, Jeju Air branding efforts are just starting. Established brands such as Southwest, Jetblue and Air Asia have built up their brand through the years through consistent and effective messages. Although the initial campaign has created plenty of buzz on SNS. Jeju Air now needs to sit back and come up with a coherent plan for the future. Should they stick with Big Bang or should they keep rotating the stars, while staying within K-Pop? Should they carry out a major ATL (above-the-line) advertising campaign to generate awareness in Korea and abroad? Should they just move within K-Pop or should they supplement their brand-building efforts with some other themes? What types of promotion events can Jeju Air carry out in conjunction with the use of their K-pop stars? These are the questions that Jeju Air needs to answer in their road to building a strong airline brand.

〈Figure 12〉 K-pop index

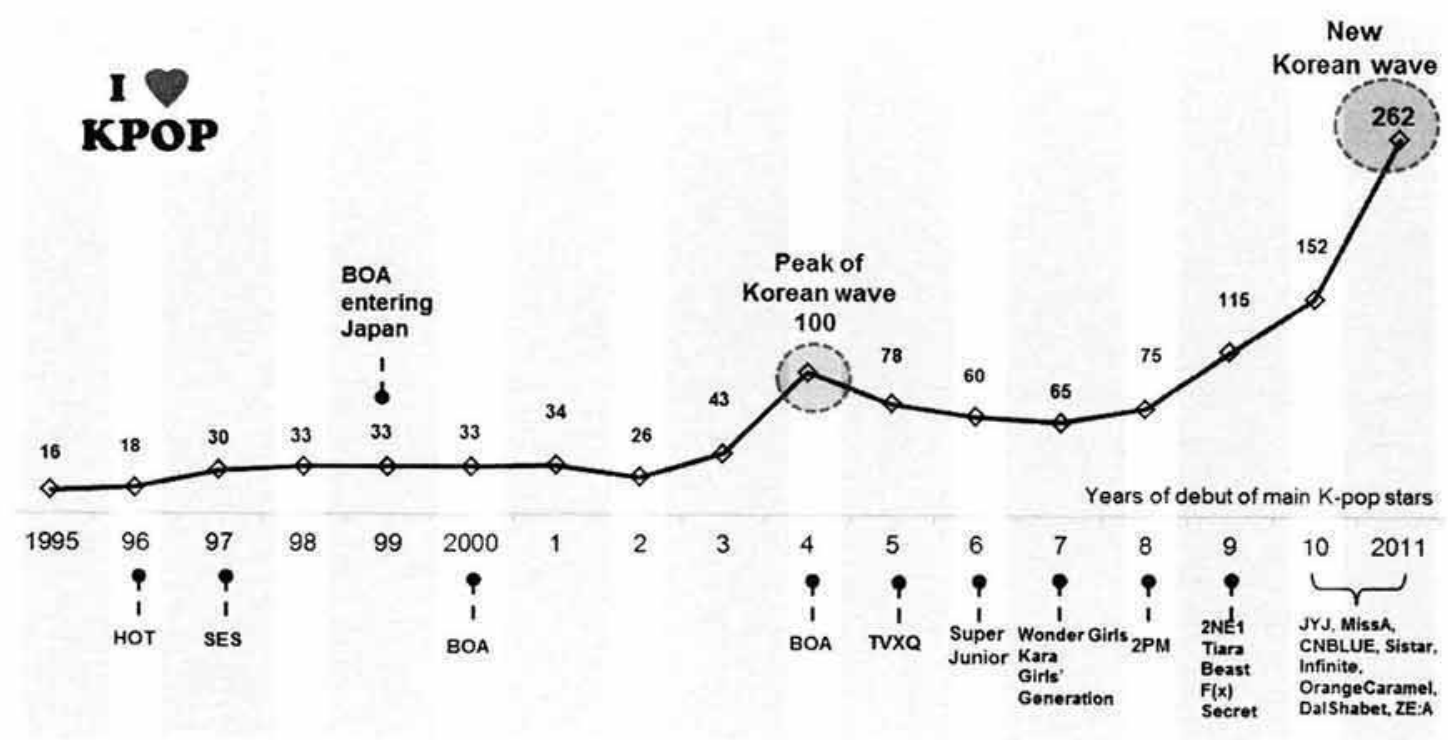

